\title{
DEVIATING FROM LINGUISTIC CORRECTNESS IN THE AUTHENTIC INPUT OUTSIDE THE CLASSROOM
}

\author{
Maja Žarković Mccray, \\ Maja Kujundžić, \\ Žana Gavrilovići \\ Faculty of Philosophy, \\ University of East Sarajevo, \\ Bosnia and Herzegovina
}

\begin{abstract}
:
Students often lack the desired authentic input in the classrooms and that is why they so often expose themselves to it by watching films, TV series or listening to popular music. This inspired our research and we decided to analyze the errors that can be found in the authentic input, which is a frequent occurrence in songs. The aim of this paper is to analyze the most popular songs at the moment, precisely those with more than one billion views on YouTube, and to answer the question if the most popular music in the world is in some way a reliable authentic input tool. We were primarily focused in our analysis on basic rules of syntax in lyrics. In the end, we analyzed 164 songs where 91 songs were linguistically correct and 73 songs linguistically incorrect. It means that more than 55 percent is correct and 44 percent incorrect. After analytic, descriptive and statistical analysis of incorrect songs, we came to a total of 230 errors divided into three categories: sentence structure (97 errors), subject-verb agreement (80 errors) and multiple negations (53 errors). We conclude that the most popular music is definitely the valuable and interesting tool, but linguistically not the reliable authentic input tool without incorporating it into classroom teaching and learning which can together with grammars, course books, dictionaries and other more reliable means for studying English influence a positive learning environment, students' motivation and correct linguistic 'feel'.
\end{abstract}

Keywords: authentic input, music/songs, intercultural speakers, linguistic 'feel'

\section{Introduction}

Intercultural speakers are persons who have managed to settle for the in-between and who know and can participate in both their native culture and in foreign one (House 2007: 19). Perhaps the more appropriate term would be cross-cultural or trans-cultural, in the sense that emphasize the fact that linguistic contact occurs between two or more languages, not within one language.

\footnotetext{
i Correspondence: email maja.zarkovicmccray@ff.ues.rs.ba; maja.kujundzic@ff.ues.rs.ba; zana.gavrilovic@ff.ues.rs.ba
} 
These types of learners are not the only ones since there are also various linguistics majors and persons who want to be proficient users of any foreign languages. The learners, usually in a foreign language context, lack the opportunities to face authentic input and chances for interaction outside the classroom (Martinez-Flor 2007: 245). It is very difficult for those learners who try to acquire English and at the same time live in countries where English is not officially spoken to be more exposed to the language they are trying to acquire (Bley-Vroman 1999: 25). That is why they turn to alternative means of broadening their knowledge or just exposing themselves to it. ii They can face authentic input by watching films, TV series or listening to music and in the process some advanced adult learners develop a "feel" for the language, which means that they feel that some expressions are right or wrong, linguistically speaking, even though they cannot state rules or, if they can, they state incorrect ones for using those expressions (BleyVroman 1999: 31).

Various definitions of music or songs by the scholars are variable, from too general or too narrow. The most relevant and interesting definitions for our research are those that see music as a set of organized sounds with a purpose (e.g. leading to activities such as listening, dancing, performing) (Levinson 1990) and songs as pieces of music and lyrics whose purpose is performance (Franzon 2008).

The recent research results clearly state that learning is optimal when the conditions for emotional or arousal and linguistic functions are fulfilled (Schön et al. 2008: 982). This inevitably invites us to indicate the link between the inner workings of the brain and learning. Leslie Hart (1983) tried to explain it more elaborately, defining neurons as key cells and the so-called switches and learning as throwing large numbers of these switches to one position or another. The number of neurons is enormously large. It is said that the left half of the cerebrum is concerned with language while the right one with visual and rhythmical patterns. There is the bridge between these two halves called corpus callosum which consists of more than two hundred million nerve fibres. That is why the brain is a very elaborate system of interconnected parts which operates by simultaneously going down many paths. Therefore, the language is full of irrational twists and turns and is far from logical (Hart 1983).

Campbell (1992) states that music has an uncanny manner of activating neurons which results in relaxing muscle tension, changing pulse, and producing long-range memory. All these activities are directly related to the number of neurons activated in the experience. It is considered that the primary factors influencing and moderating brainwave patterns are sound, especially music, and vibrational patterns, especially rhythm and beats. Millions of neurons can be activated in a single musical experience and through the activation of these neural connections learning takes place (Adkins 1997: 7).

The thought that Hart (1983) tried to point out in her work was that listening to speech is no more sequential than listening to music because music, according to Campbell (1992), has a way of utilizing the left half of the cerebrum for language and the right for distinguishing musical

\footnotetext{
iiThe necessity to expose learners of any language to authentic input is recognized by authors who use different means to familiarize learners with it and bring them closer to the speech community they are trying to understand. For more details about their studies see: Flor-Martinez (2007) who uses films or Kurata (2011) who uses informal social networks.
} 
intonations through integration via the corpus callosum. Functions of the two halves cannot, however, be completely separated but Campbell (1992) states that the more connections that can be made in the brain, the more integrated that experience is within memory.

Some of the benefits of incorporating songs into foreign language learning are: songs can motivate learners because they cover various topics such as love, dreams, friendships, culture etc. and act as a cultural database (Millington 2011; Kuśnierek 2016), songs improve learners' vocabulary learning skills (Kuśnierek 2016) and songs create a positive learning environment (Krashen 1981; Millington 2011). This positive learning environment is possible if students are involved in the process also. Songs must be interesting to them but also suitable for classes since every curriculum is created for certain purposes and with certain goals. There are many reasons for saying that music and songs are relevant for learning languages but the most significant one for our research is the power of emotional aspects of songs to increase the level of arousal and attention (Schön et al. 2008: 976).

\section{Sample and Methodology}

Acknowledging the fact that authentic input outside the classroom is not always linguistically correct, we wanted to investigate its linguistic correctness within a sample that we chose. Our research commenced with a survey at the Faculty of Philosophy in Pale, so as to establish a solid ground for further research. The survey comprised 164 students from different departments of the Faculty of Philosophy. First of all, we wanted to establish whether the students lacked the authentic input in the classroom and whether they were exposed to authentic input outside the classroom and to which extent. The results of this survey showed that $53 \%$ of all the students answered "yes" when they were asked whether they lacked authentic input in their classrooms while $47 \%$ answered "no", but $77 \%$ answered that they exposed themselves to authentic input outside the classrooms while only $23 \%$ said that they did not expose themselves to it. When asked how often they exposed themselves to authentic input, $60 \%$ answered "whenever they found time", 19\% "once a day", 10\% "once a week", 10\% "once a month" and only 1\% "never". When they exposed themselves to authentic input, 40\% listened to music, 36\% watched films, $13 \%$ watched different TV series, $9 \%$ read and only $2 \%$ watched different TV shows. Music being mostly used authentic input tool among the learners outside the classroom, we decided to further focus on that branch of art.

We premise that the authentic input in that field is linguistically incorrect to a great extent and the errors syntactically typical, which was the conclusion by a similar study where songs with more than 200 million views on YouTube were analyzed (Žarković 2017). We further hypothesize that the most popular music today should be incorporated into the classroom learning and teaching due to its far-reaching, linguistically positive or negative impact. We decided to analyze the most popular music input that the learners are exposed to in order to answer the question what feelings it is causing in them and how reliable as a tool it is. With the aim of establishing the most reliable results, we relied on convenience sampling method, since the idea was to investigate the frequency and quality of authentic input among the 
correspondents at different departments of Faculty of Philosophy. Further methods utilized were analytic, descriptive and statistical method.

Our corpus consisted of a list of songs with more than one billion views on YouTube. Why this particular group of songs? The answer is because such a broad corpus would corroborate the findings much better, and these songs are not just popular but worldwide popular. That means that learners had to hear them even if some of them did not like certain performers and that is why they became suitable input we wanted to analyze. We collected and analyzed those songs which were this popular during the research period from March 2015 over September 2021. We included pop, rock, funk, rap, hip hop, rhythm and blues and folk songs into our research. In the end, we had a collection of 164 songs where 91 songs were linguistically correct and 73 songs linguistically incorrect. It means that more than 55 percent is correct and 44 percent incorrect. If we repeat that we have 73 incorrect songs that are all around our learners given their popularity, we can say that bringing them into the classrooms and giving them necessary attention can be highly beneficial for the correct linguistic feel. Our analysis was primarily focused on lyrics of these songs ${ }^{\mathrm{iii}}$ and basic grammatical (syntactic) rules that every learner should acquire in order to use English properly. A detailed description and analysis of some typical examples form the corpus will ensue in the following section.

\section{Results and Analysis}

In examining the lyrics of the songs, we were primarily focused on the basic syntactic rules that a grammatical English sentence needs to incorporate. We divided syntactic errors into several categories: sentence structure errors, subject-verb agreement and multiple negations. In the end, we found 230 different syntactic errors in our corpus.

We start our analysis with different sentence structure errors. We found 97 errors occurring in different songs. These types of errors were mostly related to the sentences whose syntactic structure was non-existent because they omitted the necessary and grammatically obligatory elements.

3.1. We start with some typical question errors:

1) "I know that dress is karma, perfume regret You got me thinking 'bout when you were mine, oh

And now I'm all up on ya, what you expect?

But you're not coming home with me tonight."

(Charlie Puth - Attention)

2) "Players only, come on

Put your pinky rings up to the moon

Girls, what y'all trying to do?

iii We downloaded lyrics from the following websites: https://www.azlyrics.com/ and https://genius.com/ 
24 karat magic in the air

Head to toe so player

Uh, look out!"

(Bruno Mars - 24K Magic)

3) "I gave you attention when nobody else was paying

I gave you the shirt off my back, what you saying?

To keep you warm

I showed you the game everybody else was playing, that's for sure

And I was on my knees when nobody else was praying, oh Lord."

(Skrillex, Diplo feat Justin Bieber - Where Are U Now?)

All these examples show the omission of necessary auxiliary verbs from the questions, making them grammatically incorrect. The omission is present in the following examples as well, where it leads to participles functioning as main verbs:

4) Hey, said a hustler's work is never through

We makin' it 'cause we make it move

The only thing we know how to do

Said it's the only thing we know how to do.

(David Guetta, Ne-Yo and Akon - Play Hard)

5) East coast, I know you shakin right

Down South, I know you bouncin right

West coast, I know you walkin right, cause

Midwest, I see you swing it right

(You don't know what you mean to me)

East coast, you still shakin right

Down South, I see you bouncin right

West coast, I know you walkin right, cause

Midwest, I see you swingin right.

(You don't know what you mean to me) (Nelly and Kelly Rowland - Dillema)

Where the auxiliary verbs were not omitted, they were used as bare infinitives that functioned as main verbs $(6,7)$ or non-existent verb tenses $(8)$. There are examples where sentences had no verbs $(9,10)$ :

6) Yeah, my receipts be lookin' like phone numbers

If it ain't money, then wrong number

Black card is my business card

The way it be settin' the tone for me

I don't mean to brag, but $I$ be like, "Put it in the bag," yeah.

(Ariana Grande - 7 Rings) 
7) And I didn't wanna write a song

Cause I didn't want anyone thinking I still care

I don't but, you still hit my phone up

And baby I be movin' on

And I think you should be somethin'

I don't wanna hold back, maybe you should know that.

(Justin Bieber - Love Yourself)

8) Lately I been, I been losing sleep

Dreaming about the things that we could be

But baby, I been, I been prayin' hard

Said no more counting dollars

We'll be counting stars

Yeah, we'll be counting stars.

(One Republic - Counting Stars)

9) The way he makes me feel yeah, gotta hold on me

I've never met someone so different

Oh here we go

You a part of me now, you a part of me

So, where you go I follow, follow, follow.

(Shakira and Rihanna - Can't Remember to Forget You)

10) Come on, dance

Jump on it

If you sexy then flaunt it

If you freaky then own it

Don't brag about it, come show me

Come on, dance

Jump on it

If you sexy then flaunt it

Well it's Saturday night and we're in the spot

Don't believe me, just watch (come on).

(Mark Ronson and Bruno Mars - Uptown Funk)

For the purpose of illustration, just a small portion of all the errors of this type that we found in our corpus are listed and discussed here. Their abundance in the corpus does appear quite worrying. A cause for professional worry is even more highlighted by the fact that these errors sometimes repeat more than once in one song and sometimes one song contains all of them. One additional thing that is definitely alarming is the fact that these songs are worldwide popular and have been repeated and heard in so many different situations. For instance, Uptown 
Funk by Mark Ronson and Bruno Mars, for example, is the fourth most viewed song in the world with more than 4.2 billion views.

3.2. Another very present syntactic error that we found in our corpus is incorrect subject-verb agreement or concord. This concord is the most important type of concord in English because it implies the concord of the subject and predicate, i.e. a singular subject requires a singular verb form in predicate while a plural subject requires a plural verb (Quirk et al., 1985: 755; Greenbaum and Quirk 1990: 214). We found 80 examples where this concord was incorrect:

11) Now she say she gon' do what to who? Let's find out and see Cardi B, you know where I'm at, you know where I be (ooh, ooh) You in the club just to party, I'm there, I get paid a fee (bah). (Cardi B - Bodak Yellow)

12) House so empty need a centerpiece Twenty racks a table cut from ebony Cut that ivory into skinny pieces Then she clean up with her face, man I love my baby You talking money need a hearing aid You talking bout me I don't see the shade. (The Weeknd and Daft Punk - Starboy)

13) Now she got a six-year-old Trying to keep him warm Trying to keep out the cold When he looks in her eyes He don't know he is safe. (Clean Bandit, Anne-Marie and Sean Paul - Rockabye)

14) Hello from the outside At least I can say that I've tried To tell you I'm sorry for breaking your heart But it don't matter, it clearly doesn't tear you apart. Anymore (Adele - Hello)

The frequency of these errors is at times even more worrying than sentence structure errors because these concord errors are highly "catchy". For example, the song Hello (14) contains the error in chorus, which means the error is repeated many times or to be more precise, three times. If we say that the song is a smashing hit given the fact that it was released in October 2015 and reached one billion views on YouTube by the end of January 2016 and still counting (2.8 billion in September 2021), we can say that the error probably became learners' language "feel". 
Learners will not see it or hear it as an error here or somewhere else since they subconsciously feel that the incorrect part is actually correct.

3.3. The story of double or multiple negation has two sides. Double negatives sometimes occur within one clause but then they cancel each other out producing a positive value. These clauses stay syntactically negative because, for example, they require a positive tag question. The other side of this story says that multiple negatives in non-standard English are not cancelling each other out but they are intensifying the meaning (Quirk et al. 1985: 799; Greenbaum and Quirk 1990: 226).

English language acquisition in the classroom has always been about acquiring the standard version and that is why we treated double negatives as examples of errors. We found 53 examples containing this error:

15) I want that red velvet

I want that sugar sweet

Don't let nobody touch it

Unless that somebody's me

I gotta be your man

There ain't no other way

'Cause girl you're hotter than a southern California day.

(Maroon 5 - Sugar)

16) Every inch of your skin is a holy grail I've got to find

Only you can set my heart on fire, on fire

Yeah, I'll let you set the pace

'Cause I'm not thinking straight

My head's spinning around I can't see clear no more

What are you waiting for?

(Ellie Goulding - Love Me Like You Do)

17) My momma called, seen you on TV, son

Said shit done changed ever since we was on

I dreamed it all ever since I was young

They said I wouldn't be nothing

Now they always say, "congratulations" (uh)

Worked so hard, forgot how to vacation (uh-huh)

They ain't never had the dedication (uh)

People hatin', say we changed and look, we made it (uh)

Yeah, we made it (uh).

(Post Malone - Congratulations) 
18) I don't trust nobody and nobody trusts me

I'll be the actress starring in your bad dreams

I don't trust nobody and nobody trusts me

I'll be the actress starring in your bad dreams

I don't trust nobody and nobody trusts me

I'll be the actress starring in your bad dreams

I don't trust nobody and nobody trusts me

I'll be the actress starring in your bad dreams.

(Taylor Swift - Look What You Made Me Do)

If we just add that Sugar by Maroon 5 is the seventh most viewed song in the world, Love Me Like You Do by Ellie Goulding was the most noticeable song from the soundtrack for Fifty Shades of Gray, one of the most anticipated films in 2015 and Look What You Made Me Do by Taylor Swift was marked as one of the most memorable performer's comebacks breaking the record with more than 40 million views in less than 24 hours on YouTube, we can expect, due to the attention created around the most popular music in the world today, incorrect language "feel" to start developing with language users and learners.

\section{Conclusions}

The research in this paper was focused on the most popular music today, i.e. songs with more than one billion views on YouTube, with the aim of finding a valid answer to the question how reliable the authentic input outside of the classroom is and what kind of linguistic 'feel' it might lead to. For that purpose, we analyzed 164 songs and discovered 73 songs containing syntactic errors and 91 correct songs. Among 73 incorrect songs 230 errors were found and were divided into three categories: sentence structure errors, subject-verb agreement and multiple negations.

The most present type of error was the sentence structure error, but even more serious were subject-verb agreement errors and double negatives. These errors were highly repetitive in many different songs as well as in one song, as parts of chorus or other segments of the songs. The repetition made them "catchy". If we know that millions of neurons get activated in a single musical experience and through the activation of these neural connections learning takes place (Adkins 1997: 7), the repetitions cannot be ignored, but their influence has to be taken seriously. No one denies that it is necessary to acquire standard and correct version of English but also be aware of all the non-standard elements that are basic elements of everyday communication. If learners of English are intercultural speakers who are interested in participating in real life communication then we must pay special attention to non-standard English, turning it into a meaningful tool so as to enhance the standard English acquisition. That is the reason why the most popular songs stand as the perfect/imperfect authentic input tool with its errors, cultural context and the possibility of addressing the question of linguistic 'feel' before it becomes incorrect. The number and classification of the errors found in the corpus proved our initial hypothesis valid. By incorporating all these elements into classroom learning and teaching, teachers can motivate and equip learners with practical knowledge, given that theoretical 
background does not always subsume the practice of everyday communication. As suggested by Gavrilović and Kovačević (2018), the interactive learning model and a holistic approach to teaching may influence the development of students' communicative competence, and the competence, by rule, implies grammatical correctness. This approach can further address some other issues as well, such as race, varieties of English as well as sociolinguistic aspect of the use of English, which could serve as a starting point for additional research of both standard and non-standard use of English.

\section{Conflict of Interest Statement}

The authors declare no conflicts of interests.

\section{About the Authors}

Maja Žarković Mccray is an associate professor at the Faculty of Philosophy Pale, University of East Sarajevo. Her research interests are morphology, morpho-syntax, sociolinguistics and applied linguistics.

Maja Kujundžić is an associate professor at the Faculty of Faculty of Philosophy Pale, University of East Sarajevo. Her research interests are sociolinguistics, pragmatics and cognitive linguistics. Žana Gavrilović is an associate professor at the Faculty of Philosophy Pale, University of East Sarajevo. Her research interests are syntax, lexical semantics, translation studies and crosscultural communication.

\section{References}

Adkins, S. (1997). Connecting the powers of music to the learning of languages. The Journal of the Imagination in Language Learning. Volume 4: 40-48. http://www.popullar.eu/2.4.html. (Retrieved April 10, 2015).

Bley-Vroman, R. (1990). The logical problem of foreign language learning. Linguistic Analysis, 20 $(1-2)$.

https://www.google.ba/?gws rd=ssl\#q=The+Logical+Problem+of+Foreign+Language+Le arning. (Retrieved May 2, 2015).

Campbell, Don G. (1992). Introduction to the Musical Brain. Saint Louis: MMB Music Inc.

Franzon, J. (2008). Choices in Song Translation: Singability in Print, Subtitles and Sung Performance. The Translator, 14 (2), pp 373-399.

Gavrilović, Ž. and B. Kovačević. (2018). Developing communicative competence through interactive learning model in elementary school ESL teaching. European Journal of English Language Teaching, Volume 4, Issue 1, 86-95. doi: http://dx.doi.org/10.5281/zenodo.1422869 Greenbaum, S. and Quirk, R. (1990). A Student's Grammar of the English Language. Harlow: Pearson Education Limited.

Hart, L. A. (1983). Human Brain and Human Learning. White Plains: Longman Inc. 
House, J. (2007). What Is an “Intercultural Speaker?”, In E. Alcon Soler, M.P. Safont Jorda (Eds.), Intercultural Language Use and Language Learning. Dordrecht, The Netherlands: Springer, pp 7-22.

Krashen, S. D. (1981). Second Language Acquisition and Second Language Learning. Pergamon: Pergamon Press Inc.

Kurata, N. (2011). Foreign Language Learning and Use. Interaction in Informal Social Networks. London: Continuum International Publishing Group.

Kuśnierek, A. (2016). The Role of Music and Songs in Teaching English Vocabulary to Students. World Scientific News 43(1), pp 1-55.

Levinson, J. (1990). Music, Art, and Metaphysics. Ithaca: Cornell University Press.

Martínez-Flor, A. (2007). Analysing Request Modification Devices in Films: Implications for Pragmatic Learning in Instructed Foreign Language Contexts, In: E. Alcon Soler, M.P. Safont Jorda (Eds.), Intercultural Language Use and Language Learning. Dordrecht, The Netherlands: Springer, pp 245-280.

Millington, N. T. (2011). Using Songs Effectively to Teach English to Young Learners. Language Education in Asia 2(1), pp 134-141.

Quirk, R. et al. (1985). A Comprehensive Grammar of the English Language. Harlow: Longman Group Limited.

Schön, D. et al. (2008). Songs as an aid for language acquisition. Cognition 106, 2, pp 975-983.

Žarković, M. M. (2017). Is Popular Music Linguistically Correct?. The First Inernational Conference on English Language, Literature, Teaching and Translation Studies. $1^{\text {st }}$ CELLTTS. Word, Context, Time. Proceedings. (Sarajevo, 18-19 September 2015). Sarajevo: Dobra knjiga, pp 291314.

\section{Corpus sources}

AZLyrics (2021). Retrieved 14 October 2021, from https://www.azlyrics.com/

Genius I Song Lyrics \& Knowledge. (2021). Retrieved 14 October 2021, from https://genius.com/ 
Creative Commons licensing terms

Author(s) will retain the copyright of their published articles agreeing that a Creative Commons Attribution 4.0 International License (CC BY 4.0) terms will be applied to their work. Under the terms of this license, no permission is required from the author(s) or publisher for members of the community to copy, distribute, transmit or adapt the article content, providing a proper, prominent and unambiguous attribution to the authors in a manner that makes clear that the materials are being reused under permission of a Creative Commons License. Views, opinions and conclusions expressed in this research article are views, opinions and conclusions of the author(s). and European Journal of Literature, Language and Linguistics Studies shall not be responsible or answerable for any loss, damage or liability caused in relation to/arising out of conflicts of interest, copyright violations and inappropriate or inaccurate use of any kind content related or integrated into the research work. All the published works are meeting the Open Access Publishing requirements and can be freely accessed, shared, modified, distributed and used in educational, commercial and non-commercial purposes under a Creative Commons Attribution 4.0 International License (CC BY 4.0). 